\title{
Corpo e educação física: indicadores de produção científica ${ }^{1}$
}

Michele Silva Sacardo

Professora da Universidade Federal de Goiás Janaina Walkíria Brito e Silva

Laylianne Torres Fernandes de Souza Graduadas em Educação Física pela Universidade Estadual de Goiás

\section{Resumo}

O presente estudo teve como objetivo analisar as publicações referentes à temática "corpo", tendo em vista os artigos da Revista Brasileira Ciências do Esporte (RBCE) e Revista Movimento, no período de 1990 a 2010. Foram identificados 42 artigos e houve predominância da autoria individual. Podemos perceber que os artigos têm privilegiado as discussões voltadas para a área pedagógica e discussões teóricas do corpo partindo de uma visão históricocultural. Notamos que há uma concentração regional no que tange as questões sobre corpo nas regiões Sudeste e Sul, o que expressa a necessidade de expandir tal discussão para demais regiões.

Palavra-chaves: Corpo; Produção científica; Educação física.

\begin{abstract}
The present study aimed to analyze the publications related to the theme "body", in view of the articles of the Journal of Sports Sciences (RBCE) Magazine and Movement in the period 1990-2010. We identified 42 articles and predominance of individual authorship. We can see that the articles have privileged discussions focused on the pedagogical area and theoretical discussions of the body starting from a historical-cultural. We note that there is a regional concentration in terms of body issues in the Southeast and South, which expressed the need to expand this discussion to other regions.
\end{abstract} Key words: Body; Scientific production; Physical education.

${ }^{1}$ Liliane Alcântara é coautora deste artigo.

Filosofia e Educação (Online), ISSN 1984-9605 - Volume 5, Número 2, Outubro de 2013 


\section{Introdução}

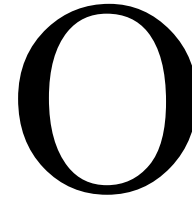

presente estudo teve como objetivo analisar os indicadores de produção científica da temática "corpo", tendo em vista os artigos da Revista Brasileira Ciências do Esporte ${ }^{2}$ (RBCE) e Revista Movimento $^{3}$, no período de 1990 a 2010.

Os indicadores de produção permitem realizar um mapeamento de determinada área do conhecimento, a partir das fontes e autores mais referendados, foco geográfico e periodização da produção. Por esses motivos, podem ser considerados como uma poderosa ferramenta de pesquisa e inovação de políticas científicas (Ivancheva, 2008). Estes estudos são úteis para mapear um campo científico de forma a identificar, por exemplo, quais são os autores e os periódicos mais citados, em que instituições se concentram os estudos de determinado tema, além de evidenciar limitações e potencialidades de melhoria da produção acadêmica da área. Publicações, autores, orientadores, palavra-chave, usuários, instituições, citações e periódicos são alguns dos parâmetros observáveis em estudos bibliométricos da literatura. Estes indicadores de produção científica, conhecidos como indicadores bibliométricos, são úteis para avaliar a pesquisa acadêmica, servem para orientar rumos e estratégias de financiamento de pesquisas, além de apontar o alcance analítico para o estudo de um campo científico.

No que diz respeito à escolha dos objetos de estudos, corroboramos com Brandão (1994) ao justificar sua escolha pela RBCE por três motivos:

O primeiro é que a RBCE é uma revista autônoma, especializada na área de Educação Física, ou seja, apesar de, em diversos momentos, receber apoio financeiro de órgãos governamentais ou apoios de instituições públicas, ela não é vinculada a quaisquer instituições a não ser o próprio CBCE. O segundo motivo é que a RBCE não possui fins lucrativos ou comerciais, tendo seu

\footnotetext{
${ }^{2}$ As publicações da Revista Brasileira de Ciências do Esporte (RBCE) são editadas sob a responsabilidade do Colégio Brasileiro de Ciências do Esporte (CBCE) sendo ela, um dos mais tradicionais e importantes periódicos científicos brasileiros na área de Educação Física/Ciências do Esporte. É indexada em indicadores internacionais, reconhecida como B2 no sistema de avaliação Qualis/Capes (2007). O CBCE é uma entidade científica que congrega pesquisadores ligados à área de Educação Física/Ciências do Esporte, ligado à Sociedade Brasileira para o Progresso da Ciência, está presente nas principais discussões relacionadas à área de conhecimento.

${ }^{3}$ A Revista Movimento é o periódico da Faculdade de Educação Física da Universidade Federal do Rio Grande do Sul, a qual teve periodicidade anual em 1994, semestral de 1995 a 2001, quadrimestral de 2002 a 2008 e trimestral de 2009 em diante.
} 
interesse centrado na produção científica do conhecimento. O terceiro motivo é o fato da RBCE, enquanto revista autônoma, ser a mais antiga revista brasileira especializada em Educação Física em plena atividade e circulação no momento (...) (Brandão, 1994, p.12).

Já em relação à relevância da Revista Movimento, Brito Neto et. al. relatam:

A Revista Movimento acumulou uma série de conquistas ao longo desses aproximadamente quinze anos de existência, podemos elencar: a) A sua consolidação, através das 36 edições completadas no final de 2008; b) Reconhecimento da comunidade científica brasileira devido a sua periodicidade, regularidade e qualidade das suas publicações; c) Referência na Educação Físi ca Brasileira a partir da sua especificidade de constituir-se em um periódico vincula do às Ciências Humanas e Sociais d) Compromisso com a ampla divulgação das descobertas científicas na área da Educação Física através da sua edição eletrônica que possibilita socializar e disponibilizar todas as edições da Revista, sem custos; d) Ampliação do impacto da revista, com a sua inserção no âmbito internacional, publicando uma versão eletrônica também na Língua Inglesa; e) Estímulo ao debate e a reflexão sobre os objetos de conhecimento a partir de diferentes enfoques, como foi possível evidenciar na clássica seção 'temas polêmicos’ (Brito Neto et. al., 2009, p. 4).

Assim, as preocupações acerca do corpo não são fruto da modernidade, como ressaltou Manacorda (2001), havia uma preocupação com o corpo na Grécia do século V a.C. onde existia o ginásio, forma típica da "escola" grega, destinada apenas às crianças de famílias ricas, constituindo um centro de cultura física e intelectual. Era destinado aos exercícios físicos a serem praticados nus pelos "educandos", tornando-se posteriormente lugar de exercitações culturais e filosóficas. Nessas escolas havia uma formação mais esportiva a intelectual. Em seguida, paulatinamente, apesar de um período de euforia da ginástica entre os séculos II e III d.C., as exercitações intelectuais tiveram a prevalência e a antiga unidade entre físico e intelectual estariam definitivamente perdida.

Ainda, nesta mesma linha de raciocínio por intermédio de Protágoras, Platão explica que as crianças nas escolas de Atenas eram enviadas ao mestre da ginástica, para que, sendo seus corpos mais fortes, obedecessem melhor as boas disposições da inteligência e não se tornassem fatalmente covardes, quer em guerra quer em outras ações, pela fraqueza de seu corpo.

Em outro aspecto, autores da área da Educação Física, tais como Romero (1995), Gonçalves (1997); Medina (1997 e 1998), Soares (2001a, 2001b e 2002), Bruhns (1997); Daolio (2003) Carmo Junior (2005) 
realizaram estudos sobre o corpo e corporeidade apresentando similitudes em suas concepções. Esses estudiosos enfocaram aspectos sociais e culturais, e também apontaram uma visão geral do corpo para além das análises subjetivas e mecanicistas sobre o assunto em questão. Os aspectos destacados por esses autores lançam luz à análise da dominação do corpo no campo social, e elucidam tal domínio corporal através do discurso da alienação, de modo que esta constitui a forma mais especifica para se chegar ao objetivo do ser sujeito dominado.

Já em outra perspectiva, Vaz (1999) desenvolveu uma análise teórica sobre o treinamento corporal baseada na lógica sacrificial e na correspondente redução do corpo a uma naturalidade desqualificada e fungível. Para tanto, utilizou a teoria da formação do sujeito e da civilização desenvolvida por Theodor W. Adorno e Max Horhkeimer, sobretudo na Dialética do Esclarecimento, enfatizando o papel do sacrifício nesse processo e a relação deste com o corpo, procurando a partir desse pressuposto o esporte, e, dentro dele, o treinamento corporal.

Outro estudo foi o de Baptista (2007) que analisou as mediações histórias determinantes da forma do corpo e a educação deste no contexto capitalista. Questionou como se determina a forma do corpo na sociedade atual. A partir de referenciais pautados em Karl Marx, Friedrich Engels, Theodor Adorno, Max Horkheimer e Georg Lukács, o autor ainda buscou a compreensão da Indústria Cultural, permitindo-lhe uma análise atual do debate. Os apontamentos realizados por Baptista evidenciaram o ideal estético - do corpo na sociedade capitalista atual é determinada pelos interesses de produção e de consumo do capitalismo e que a Indústria Cultural dissemina um modelo de juventude, magreza, força e resistência, consolidando a educação do corpo enquanto corpo fetichizado e reificado.

De fato, a Indústria Cultural abordada por Adorno e Horkheimer (1985), procura compreender as condições de produção e reprodução social em uma de suas faces mais importantes, relacionada à mercantilização da cultura, sua banalização e reificação, onde a cultura passa a ser produzida na esfera da circulação e do consumo para o entretenimento e ocupação do tempo livre. 
Diante dos estudos mencionados acima, temos observado que a temática sobre "o corpo" a partir das análises de seus indicadores de produção na RBCE e na Revista Movimento ainda são escassos, quando se leva em consideração seus determinantes histórico-sociais e suas implicações para a área da Educação Física.

Com o advento da produção científica na área da Educação Física, no início dos anos de 1980, observarmos que apesar dos avanços dessa produção em relação à temática corpo, ainda se faz necessária análises mais concretas que leve em consideração seus determinantes mais amplos (históricos, filosóficos, econômicos e sociais) os quais determinam e condicionam a construção histórica tanto de fenômenos sociais quanto dos conhecimentos produzidos por um campo científico.

Nessa perspectiva, este estudo levantou a seguinte questão norteadora: Quais as características das publicações científicas que discutem a temática "corpo" nos artigos da Revista Brasileira de Ciências do Esporte e da Revista Movimento de 1990 a 2010, no que se refere à periodização dos artigos, presença de colaboração científica nas autorias dos artigos, foco geográfico das pesquisas, as temáticas privilegiadas, bem como as principais recomendações/indicações?

Os objetivos foram: a) Identificar quais são os artigos que discutem o corpo no período de 1990 a 2010 na Revista Brasileira de Ciências do Esporte e na Revista Movimento, em relação ao comportamento de publicação de autores, temáticas privilegiadas e as principais recomendações/indicações; c) verificar quais os aportes teóricos que fundamentam a discussão sobre a temática "corpo" nos artigos publicados na Revista Brasileira de Ciências do Esporte e da Revista Movimento.

\section{Procedimentos metodológicos}

O estudo pode se caracterizar como uma pesquisa bibliográfica/documental de cunho descritiva por envolver leitura, seleção e registro de literatura de interesse para o estudo proposto. A partir dos artigos publicados na Revista Brasileira de Ciências do Esporte e Revista Movimento, de 1990 a 2010 , 
selecionamos apenas aqueles artigos com enfoque nas temáticas sobre o corpo.

Por meio da análise de conteúdo (Bardin, 2006), procedemos à organização do material ou pré-análise a qual foi realizada por meio da confecção das fichas de conteúdo. A codificação ou descrição analítica foi caracterizada pela identificação das temáticas recorrentes nos artigos e pela interpretação referencial. Assim, os textos dos artigos foram examinados a partir da análise de conteúdo, nos parâmetros apresentados por Bardin (2006) que afirma tratar-se de uma técnica que permite o exame metódico, sistemático e objetivo do conteúdo de certos textos, a fim de classificar e de interpretar os elementos constitutivos que não estão totalmente acessíveis em uma leitura superficial.

Primeiramente, localizamos, a partir de um exame dos títulos de todos os artigos, a presença da temática "corpo", no recorte temporal - 1990 a 2010 - em ambas as revistas. Após essa seleção, os artigos foram lidos na íntegra e categorizados de acordo com instrumento confeccionado e o referencial teórico adotado. Os dados foram organizados a partir de uma ficha - instrumento de coleta - descritiva e explicativa que possibilitou o destaque de categorias organizadoras. Os elementos que constituíram esse o instrumento (ficha) foram: I - Fonte de Informação (RBCE e Revista Movimento); II - Título do artigo; III - Autor (es) e Instituição; IV Ano/Vol./N. do periódico em que foi localizado o artigo; V - Palavraschaves; VII. Foco geográfico do artigo; VIII - Objetivos e contribuições dos artigos.

Esta categorização nos permitiu uma leitura particular das unidades de registro temáticas e as possíveis reflexões sobre o corpo a partir do diálogo com a literatura pertinente, fundamentando nossa preocupação com a problemática investigada.

\section{Descrição dos resultados}

Neste momento apresentaremos a organização dos resultados das pesquisas, caracterizando os artigos publicados na RBCE e na Revista Movimento, voltadas para a temática “corpo” no período de 1990 a 2010. 
Inicialmente realizamos a identificação dos artigos a partir de um exame dos títulos de todos os artigos, quanto a presença da temática "corpo", no recorte temporal -1990 a 2010 - nas revistas RBCE e Movimento. Foram identificados 42 artigos científicos nas Revistas RBCE e Movimento, voltados para temática "corpo" no período de 1990 a 2010, sendo 23 (55\%) artigos foram publicados na RBCE e 19 (45\%) na Revista Movimento.

Os artigos foram lidos na íntegra para a realização da coleta de dados, que ocorreu através do preenchimento de uma ficha roteiro, que originou as seguintes categorias: Periodização dos artigos, Colaboração científica nas autorias dos artigos, Foco geográfico das pesquisas e Temáticas privilegiadas.

A figura abaixo apresenta como ficaram distribuídos os artigos analisados ao longo dos anos.

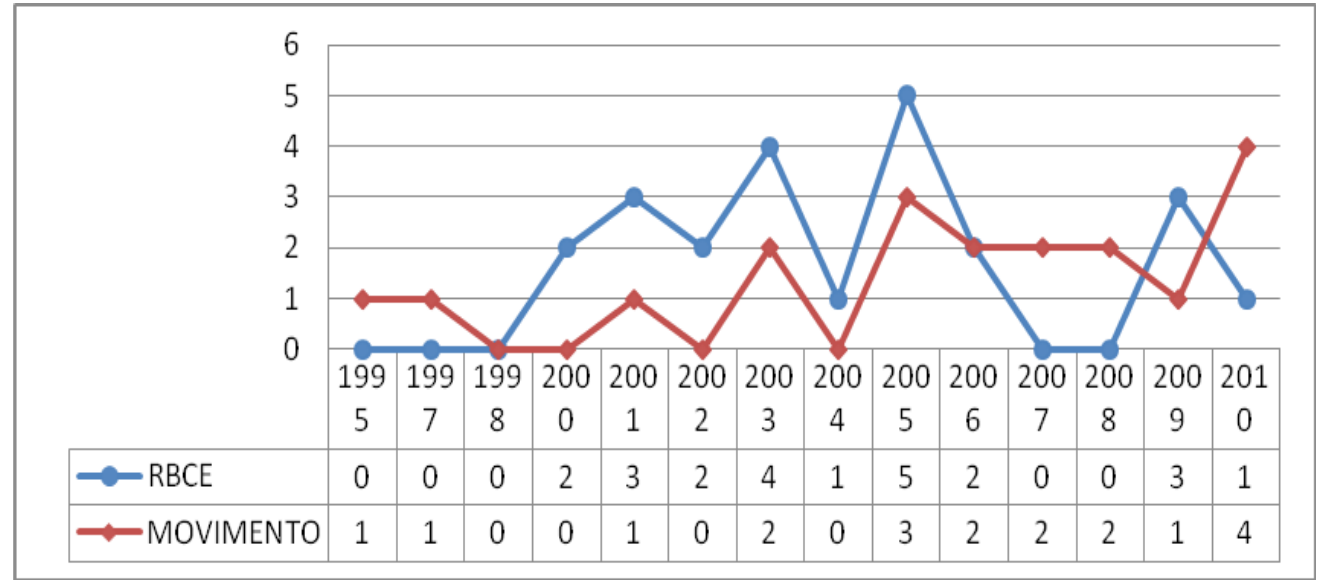

Figura 1 - Distribuição dos artigos por ano

Ao longo de 15 anos de publicações sobre a temática corpo nas Revistas RBCE e Movimento, podemos perceber que o maior número de publicações por ano ocorreu em 2005 (8 artigos), e um dos supostos motivos pode estar relacionado com o fato de que os volumes da RBCE, do período de 1992 a 2008, possuir uma temática definida. Neste ano específico seus volumes contemplaram as temáticas: Linguagem, Comunicação, Mídia e Educação Física/Ciências do Esporte (1 trabalho); Infância e Educação Física/Ciências do Esporte (2 trabalhos); e Doping, Desempenho e Vida (2 
trabalhos). O quadro abaixo apresenta as autorias dos trabalhos por revista.

Quadro 1 - Autoria dos trabalhos por revista

\begin{tabular}{|c|c|c|c|c|c|}
\hline \multirow{2}{*}{$\begin{array}{c}\text { Número de } \\
\text { autores }\end{array}$} & \multicolumn{2}{|c|}{ RBCE } & \multicolumn{2}{c|}{ Movimento } & Total \\
\cline { 2 - 6 } & Artigos & $\%$ & Artigos & $\%$ & \\
\hline 1 Autor & 17 & $74 \%$ & 11 & $58 \%$ & $28(67 \%)$ \\
\hline 2 Autores & 4 & $17 \%$ & 4 & $21 \%$ & $08(19 \%)$ \\
\hline 3 Autores & 2 & $9 \%$ & 2 & $11 \%$ & $04(10 \%)$ \\
\hline 4 Autores & 0 & $0 \%$ & 1 & $5 \%$ & $01(2 \%)$ \\
\hline 5 Autores & 0 & $0 \%$ & 1 & $5 \%$ & $01(2 \%)$ \\
\hline & 24 & $100 \%$ & 19 & $100 \%$ & $42(100 \%)$ \\
\hline
\end{tabular}

Quanto à autoria, 28 do total de artigos, privilegiou a autoria individual, representando 68\%, sendo $74 \%$ dos artigos da RBCE (17 artigos) e 58\% da Revista Movimento (11 artigos). A co-autoria representou $33 \%$ do total de artigos (14 artigos), sendo 42\% (8 artigos) dos artigos da Revista Movimento e $26 \%$ da RBCE (6 artigos).

Os 42 artigos identificados nas revistas RBCE e Revista Movimento no período de 1990 a 2010 foram de responsabilidade de 65 autores, 31 autores na RBCE e 34 autores na Revista Movimento. Os autores com o maior número de ocorrência foram: Carmem Lúcia Soares com 8 ocorrências (1 na RBCE e 7 na Revista Movimento), e Alexandre Vaz com 6 ocorrências (3 na RBCE e 3 na Revista Movimento).

$\mathrm{O}$ vínculo institucional foi determinado pela instituição mencionada no artigo lido, mais especificamente, priorizamos o vínculo de trabalho. Foram identificadas 29 instituições, sendo apenas 2 (7\%) internacionais: Université de Paris Vécole dês Hautes Etudes em Sciences Sociales Paris/França e Universidade do Porto - Portugal.

A figura 3 demonstra a distribuição do número de ocorrências ${ }^{4}$ das instituições nacionais por Região.

\footnotetext{
${ }^{4} \mathrm{O}$ número de ocorrências refere-se ao número de vezes que determinada informação apareceu nas publicações
} 


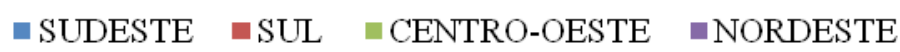

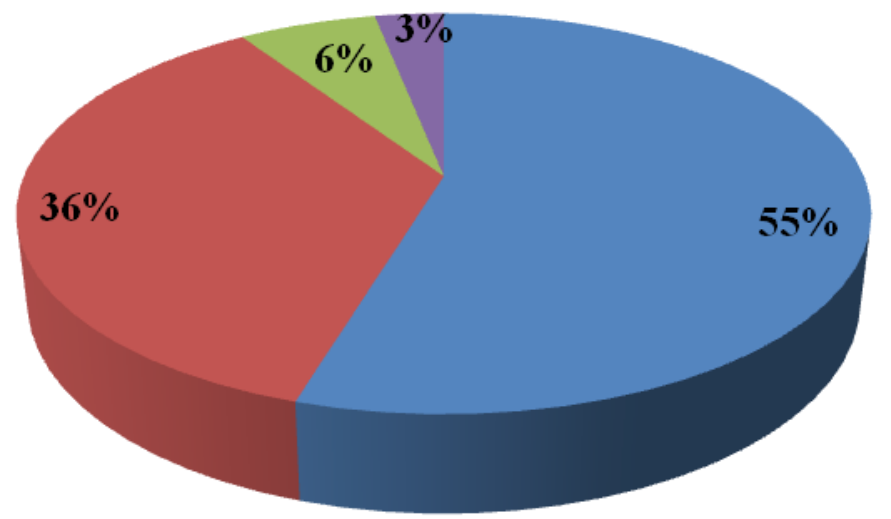

Figura 3 - Distribuição regional das instituições que os autores estão vinculados.

Quanto à distribuição regional do vínculo institucional dos autores, a região sudeste foi a que representou o maior incidência, com 35 ocorrências (55\%), seguida da região Sul com 23 ocorrências (36\%), a Região CentroOeste com 4 ocorrências (6\%) e a Região Nordeste com 2 ocorrências (3\%). Não foi identificado nenhum autor vinculado a instituições da Região Norte. O quadro abaixo demonstra a instituições que os autores das instituições da Região Sudeste estão vinculados.

Quadro 1 - Distribuição da vinculação institucional da Região Sudeste

\begin{tabular}{|c|c|l|}
\hline Estado & $\begin{array}{c}\text { Ocorrências } \\
\text { por Estado }\end{array}$ & \multicolumn{1}{|c|}{ Instituições } \\
\hline São \\
Paulo
\end{tabular}

Na Região Sudeste a distribuição do vínculo das instituições por 
Estado, demonstrou que São Paulo (17 ocorrências), Rio de Janeiro (12 ocorrências) e Minas Gerais (6 ocorrências), não foi identificado nenhum autor vinculado a instituições do Espírito Santo.

Na Região Sul a distribuição do vínculo das instituições por Estado, demonstrou que Santa Catarina (12 ocorrências), Rio Grande do Sul (08 ocorrências) e Paraná (3 ocorrências). Destaca-se o fato de todos os trabalhos de Santa Catariana serem da Universidade Federal de Santa Catarina. O quadro abaixo demonstra a instituições que os autores das instituições da Região Sul estão vinculados por Estado.

Quadro 2 - Distribuição da vinculação institucional da Região Sul

\begin{tabular}{|c|c|c|}
\hline Estado & $\begin{array}{l}\text { Número de } \\
\text { ocorrências }\end{array}$ & Instituições \\
\hline Santa Catarina & 12 & $\begin{array}{l}\text { Universidade Federal de Santa Catarina - UFSC } \\
\text { (12) }\end{array}$ \\
\hline $\begin{array}{l}\text { Rio Grande do } \\
\text { Sul }\end{array}$ & 08 & $\begin{array}{l}\text { Universidade Federal do Rio Grande do Sul (7), } \\
\text { Universidade Luterana do Brasil - ULBRA (1), }\end{array}$ \\
\hline Paraná & 03 & $\begin{array}{c}\text { Universidade Estadual do Centro Oeste (1), } \\
\text { Universidade Estadual de Maringá - UEM (1), } \\
\text { Universidade do Estado do Paraná (1) }\end{array}$ \\
\hline
\end{tabular}

A Região Centro-Oeste com 5 ocorrências (\%), sendo 2 ocorrências da Universidade de Brasília-DF, e 3 ocorrências de instituições do Mato Grosso, Universidade Estadual do Mato Grosso/MT (2) e Universidade Federal do Mato Grosso/MT (1). Os Estados de Goiás e Mato Grosso do Sul não houve nenhuma ocorrência. A Região Norte com 2 ocorrência, sendo da Universidade Federal do Rio Grande do Norte/RN e Universidade Estadual de Santa Cruz/BA.

\section{Temáticas}

Os 42 artigos identificados foram agrupados de acordo com a temática central do mesmo, esta temática foi identificada a partir da leitura completa dos estudos, assim como da relação entre título, palavras-chave e objetivo.

Este agrupamento originou 8 grupos temáticos: a) Corpo e Educação (10 artigos); b) Corpo e Cultura (9 artigos); c) Corpo e Estética (7 artigos); d) Corpo e Gênero (6 artigos); e) Corpo e Saúde (5 artigos); f) Corpo e Ginástica (3 artigos); g) Corpo e Trabalho (1 artigo); e i) Corpo e Formação (1 artigo). 
O gráfico abaixo demonstra a distribuição dos artigos por temáticas.

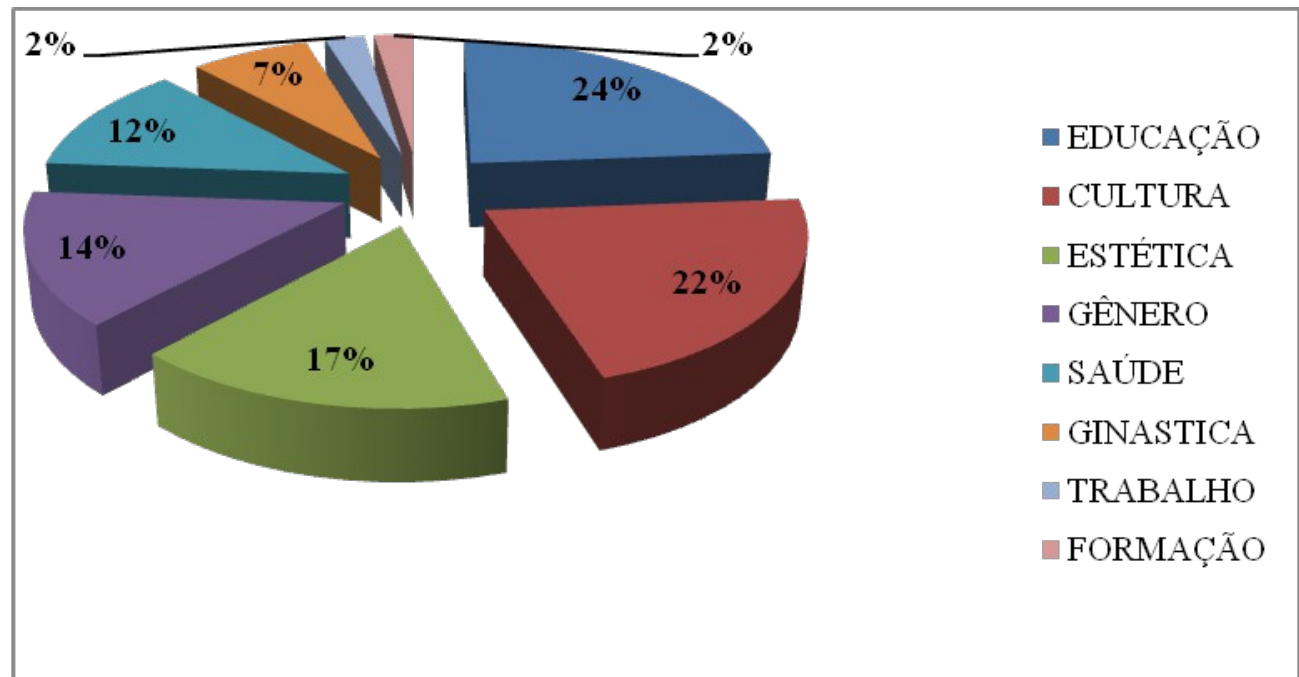

Figura 2 - Distribuição dos artigos por temática

As temáticas privilegiadas foram Corpo e Educação (24\%), Corpo e Cultura (22\%) e Corpo e Estética (17\%), estas unidas correspondem a 25 dos 42 artigos identificados, correspondendo a $63 \%$ do total de artigos.

Os estudos da subtemática Corpo e Educação compreendem estudos de campo que tiveram como lócus de pesquisa escolas, creches e um hospital. Houve predomínio dos estudos dedicados à educação do corpo na Educação Infantil. Os trabalhos sobre educação do corpo na Educação infantil tiveram como objetivo refletir sobre a ideia de infância aliada à proposta de Educação Física escolar nos anos de 1930 e 1940 no Brasil; Observar e analisar elementos para a composição de uma agenda de estudos sobre a educação do corpo; Levantar alguns aspectos relacionados à temática corpo e movimento e às diferentes formas como o tema é tratado na escola, especialmente nas séries iniciais e na educação de 0 a 6 anos; Descrever quais as implicâncias e conseqüências explícitas na educação infantil que, mediante a ação dos educadores, interferem no equilíbrio energético e emocional da criança; identificar o lugar da Educação Física na Educação Infantil em uma creche. E fizeram as seguintes recomendações: torna-se cada vez mais evidente que, para pensar a educação física no âmbito do trabalho pedagógico com crianças de pouca idade; faz-se necessário articularmos diferentes áreas do conhecimento e diferentes 
profissionais; e necessidade de alargar a relação entre todos os profissionais responsáveis pela formação dos pequenos, ao voltarem seu olhar aos espaços e tempos, aos gestos, palavras e ações que se inscrevem sobre o corpo em todos os momentos que configuram o dia a dia de trabalho nos ambientes educacionais.

Os principais objetivos dos demais estudos da temática Educação do corpo foram: discutir o ensino da Educação Física para além de seu aspecto biológico, investigar a educação do corpo a partir da teoria maussiana, divulgar alternativas pedagógicas no ensino da Educação Física em classe hospitalar, discutir as relações entre um projeto político pedagógico de uma escola plural e as praticas corporais que acontecem em uma escola de ensino fundamental. Em relação às principais recomendações estes destacaram: a aprendizagem das técnicas do corpo correspondem a um processo em que o ser biológico e social não podem ser pensados separadamente e podem contribuir para eliminação de teorias racistas que tendem a compreender o homem como resultado de seu corpo; é preciso pautar os limites corporais como uma questão a ser incorporada de forma direta no trabalho pedagógico; necessidade de valorizar os conhecimentos e experiências que os alunos trazem consigo com vistas a sua possível reelaboração; necessidade de trabalhar com mais densidade as memórias dos alunos internados no que se refere às práticas corporais; e a importância de estudar a Educação Física no contexto da classe sem desvinculá-la de outras disciplinas do conhecimento; a Educação Física tem possibilidades de contribuir para a construção de uma escola mais atenta à dimensão corporal de seus alunos; o trato com o movimento corporal não deve, de modo algum, continuar a ser terreno exclusivo deste componente curricular. Acredito, entretanto, ser fundamental que a Educação Física - tanto no contexto disciplinar como nas ações interdisciplinares, projetos coletivos, etc. - consolide sua atuação como área de conhecimento que possui um objeto de estudo específico; é necessário que a Educação Física amplie sua "interface" com as demais áreas e com o campo pedagógico de uma forma geral, porém sem abrir mão da sua especificidade.

A subtemática Corpo e cultura compreende os estudos teóricos que 
apresentam uma análise histórico-fillosófica e compreendem o corpo como objeto cultural. Estes estudos privilegiaram os objetivos: ler no corpo a sociedade; refletir sobre as questões básicas do homem corporal/resgatar a história do corpo; discutir a concepção de corpo das ciências biomédias; discutir historicidade da relação entre Educação Física, Linguagem e arte/Educação poética do corpo; analisar a construção do sentido éticoestético do corpo na cultura popular/técnicas corporais. As principais recomendações foram quanto à importância da pesquisa antropológica e incorporação da arte para a Educação Física ("A incorporação da arte nas reflexões concernentes à Educação Física poderia auxiliar na configuração de uma outra lógica para pensar o corpo e todos os fenômenos a ele ligados, inclusive no que diz respeito a sua expressão gestual. Pensar a arte como forma de conhecimento talvez permitisse superar dicotomias clássicas presentes no modo de conceber e pensar o corpo”). E alertam os profissionais de Educação Física quanto à importância de estarem atentos ao papel do corpo na cultura (" $A$ intenção destas reflexões foi somente a de alertar que os profissionais de educação física, por trabalharem com o homem através do seu corpo, estão trabalhando com a cultura impressa nesse corpo e expressa por ele. Portanto, mexer no corpo é mexer na sociedade da qual esse corpo faz parte" - Ficha 26). Ao ambiente escolar, relatam a necessidade de reflexão das questões relacionadas ao corpo e à cultura pelos educadores.

A subtemática Corpo e estética compreende pesquisas bibliográficas e de campo que buscam relacionar a influência e os desdobramentos da indústria cultural na imagem corporal e nas práticas corporais, dois dos estudos de campo ocorram em academias e três das pesquisas bibliográficas se destinaram a análise de revistas. Os estudos que buscaram identificar a influência da mídia na divulgação do corpo ideal, analisaram as revistas Boa Forma e Capricho. Estes objetivam investigar constituição de um certo “dever ser" feminino em prescrições da revista Boa Forma; examinar as estratégias discursivas presentes na revista Boa Forma que relacionam o estilo de vida com a estética corporal e a saúde; esmiuçar s mensagens escritas e visuais associadas ao culto ao corpo; e discutir a promoção do 
estilo atlético como uma forma de produção de uma representação do corpo adolescente feminino contemporâneo na revista Capricho. E fazem as seguintes indicações: a vontade de desfrutar da valorização social de ser bela fomenta uma responsabilização feminina diante de seu corpo e incita e legitima a ideia que a própria mulher deve reconhecer e exercer, por meio do sacrifício, da racionalização e do esquadrinhamento de seu corpo; a revista reforça a noção de culpabilização da mulher frente aos fenômenos construídos socialmente; as informações contidas nas revistas, não raro, estimulam intervenções para transformação do corpo e os produtos a ela associados fazem parte da aposta para alcançar um padrão estético que, referendado por especialistas, subsume novas obrigações morais.

Os demais estudos da temática Corpo e estética tiveram como objetivo: relacionar à presença do treinamento desportivo nas práticas de modelação corporal em academias de ginástica e musculação; entender o risco no processo de construção do corpo belo, perfeito e desejado; Analisar o discurso sobre as representações de corpos masculinos, frequentadores de academias de ginástica. E concluíram que os discursos e técnicas do treinamento esportivo são mediadores no processo de construção do corpo delineado e/ou atlético; é necessária na Educação Física a reflexão sobre os riscos na busca desenfreada pelo corpo ideal; a crescente obsessão compulsiva pela musculatura, o uso e abuso de ingestão de drogas e esteróides anabolizantes como parte da iniciação dos jovens que praticam musculação; e denunciar o modo como nossa sociedade supervaloriza o corpo belo, forte, novo e produtivo, gerando diversas formas de preconceito e de descriminação praticadas pelas sociedade moderna e contemporânea.

A subtemática Corpo e gênero compreendem pesquisas de campo que contemplaram discussões sobre: representação do corpo feminino nos espaços sociais e importância do corpo como marcador de gênero nas experiências de sociabilidade do grupo. E concluíram que tais questões "envolvem disputa de valores, de poder, de tipos de comportamento legitimados, de normas e de verdades e que estes podem, pois, ser entendidos e problematizados como um lugar de luta constante pela manutenção daquilo que cada sociedade define como estado de 
normalidade" e compreendem o corpo "como um potente marcador social da contemporaneidade”. Destaca-se o uso da técnica de grupos focais em dois destes trabalhos, os quais se embasaram na perspectiva teórica pósestruturalista de Michel Foucault.

Os artigos da subtemática Corpo e saúde são estudos teóricos que vêm o intuito de romper com visão fragmentada e mecânica do corpo. Estes tiveram como objetivo principal: evidenciar a importância das áreas da medicina e da educação física; discutir mudanças que vêm ocorrendo na biologia, as quais contribuem para problematizar a visão mecanicista de mundo e de homem e suas implicações para o corpo e a Educação Física e discutir o papel da educação física voltada para saúde. E fazem as seguintes recomendações: a relação corpo e saúde não deve ser estudada a partir de uma visão fragmentada, pois “esses componentes não se apresentarão separados, mas, ao contrário, articulados a fatores que se interligam e se inter-relacionam influenciando-se reciprocamente" (FICHA 2R); a necessidade do entrelaçamento das ações biológicas aos fenômenos sociais e a diversidade cultural, assim "em vez de refutar os estudos biológicos, busque novos referenciais nessa área do conhecimento, de modo que possa proporcionar a comunicação entre as ciências naturais e humanas ultrapassando o pensamento disjuntivo advindo da fragmentação dos saberes cientificos" (17R); e a importância de refletir criticamente ao falso discurso atrelado a concepção corpo saudável, desta forma a "educação fisica, a partir de cada professor, quiser dar sentido a sua existência e relacionar-se à saúde, deve começar por estar vigilante às 'promessas de felicidade', às quais poucos podem resistir e ao processo de exclusão, que amiúde ela corrobora" (15R).

Os estudos da subtemática Corpo e ginástica tiveram como objetivo buscar os motivos que levaram o corpo do homem fluminense a rejeitar essa prática corporal, tornando o Rio de Janeiro o não-lugar da ginástica; compreender as práticas corporais desenvolvidas no Sport Club Germania e observar suas possíveis relações com a ginástica desenvolvida largamente na Alemanha ao longo do século XIX; descrever a história do surgimento da ginástica. E concluíram que: $\mathrm{O}$ corpo do homem fluminense encontrou-se 
ali uma "alma" incompatível com os preceitos de uma ginástica racional, que idealizava e esquadrinhava os corpos; diferente dos outros clubes alemães do período, o Germania não tinha a ginástica como principal atividade, o que não significa dizer que esta prática fosse inexistente em seu interior e a presença de um departamento voltado para sua aplicação destinada aos jovens da colônia atesta, sem duvida, sua importância; e a criação de novos corpos devido a invenção da ginástica e dos novos movimentos.

Com apenas um artigo, foram identificadas as subtemáticas Corpo e trabalho e Corpo e Formação. O artigo da subtemática Corpo e trabalho compreendeu uma análise teórica da relação entre corpo e trabalho ao longo da história e as dicotomias presente neste processo. E concluíram que a visão remota e atrasada do corpo como motor, "que fora fruto da limitação produtiva e teórica de uma determinada época" (p. 13) ainda se faz presente, esta concepção contribui para a "desconsideração da corporeidade nos estudos sobre o trabalho" (p.13). Existem diferentes concepções da relação entre corpo e trabalho, que "ora o vêem como ultrapassado pela cognição, ora o consideram como base do comportamento inteligente, e estudam a inteligência operária por meio dele". Ainda timidamente vem crescendo novas compreensões sobre o corpo no interior dos processos produtivos representando "a fase produtiva mais avançada". E alerta para o fato do "descuido em relação ao estudo das relações entre corpo e trabalho dificulta, dessa maneira, uma maior compreensão das transformações culturais, das novas configurações dos embates politicos e dos dilemas econômicos que têm lugar no capitalismo hodierno" ( p. 13)

Já o da subtemática Corpo e Formação compreendeu um estudo de campo que teve como objetivo identificar a concepção de corpo dos graduandos de Educação Física, constatou “a predominância de uma visão técnico-biológica e fragmentada de corpo no primeiro período e, nos últimos, uma compreensão mais integrada de corpo". Detectou-se, também, haver consenso entre os graduandos, de que o professor de Educação Física interfere na visão de corpo dos seus alunos, basicamente através da orientação sobre questões associadas à saúde, à estética e à técnica (Ficha 
41, p. 14).

\section{Discussões}

As evidências temáticas, os objetivos e considerações destacadas nos artigos analisados nesse estudo permitem-nos pressupor a relação intrínseca que há entre corpo-educação; corpo-cultura; corpo-estética; corpo-genero; corposaúde; corpo-ginástica, e corpo-trabalho e formação, não como algo dicotômico em função da dialogacidade existente entre eles, haja vista sua real historicidade desde a formação do homem em sociedade até a hodierna contemporaneidade, lógico que assumindo roupagens ora semelhantes ora distantes mediante o contexto histórico situado.

Dessa forma, ao relacionar corpo e educação se faz necessário a compreensão da influência da interligação entre escolas, creches no paradigma do discurso do corpo dominado e dominante via disciplina dos corpos como ressalta os estudos de Foucault (1986; 1987). Sendo que no ambiente escolar, percebe-se a relação do corpo com o processo educacional de domínio e disciplina, onde o corpo é milimetricamente pensado e coordenado no espaço e tempo e qualquer atitude fora desses padrões e tido como transgressão devendo de imediato ser punido, seja por meios físicos ou psicológicos.

Nesse contexto ainda suscitam fica a dúvida, até que ponto às nuances da educação física como vivencia livre de corpo tem propiciado aos alunos vivências motoras amplas que valorizem o seu repertório histórico-cultural e, em que medida as amarras da disciplina ainda circundam o ambiente escolar? A educação física tem ficcado à margem das perspectivas educacionais atuais ou simplesmente tem sido considerada um horário para recreação ou prática esportiva descontextualizada e alienada?

Assim, vale ressaltar os estudos de Perrot (1988) ao mencionar a educação física enquanto disciplina somática, no sentido de cuidar do físico, sendo assim necessária.

(...) para que a nova ordem e a nova racionalidade exigidas pela instauração da sociedade industrial fossem criadas; isso porque era necessário transformar camponeses e andarilhos em operários (...) três formas de disciplina criam uma nova corporeidade: a era do olhar, marcada pelas 
diversas formas de fiscalização; a disciplina fabril, como resultado de uma organização administrativa; e a ciência do trabalho, que tem no corpo um objeto de estudo buscando a maximização do rendimento (Perrot, 1988, p. $53)$.

No que tange ao contexto do corpo enquanto cultura é nítido a desvalorização atual do acervo que o corpo do aluno tem ao chegar ao ambiente escolar, ele possui infindáveis linhas escritas sobre o processo histórico-cultural do sujeito que o carrega. Negligenciar isso é tão grave quanto negar as tragédias mundiais, que tiveram por objetivo exterminar rasas inteiras como os judeus nos campos de extermino na segunda guerra mundial.

Para Daolio, (2007) o termo cultura faz parte da educação física, surgindo há duas décadas influenciando a área e, que após um longo período de explicações corporais baseadas nos pressupostos biológicos começa a mudado por conhecimentos advindos das ciências humanas. Com isso a educação física passa a lidar com conteúdos culturais e o corpo passa a ser visto como uma expressão da cultura.

Tenho afirmado em outros trabalhos que "cultura é o principal conceito para a educação física, porque todas as manifestações corporais humanas são geradas na dinâmica cultural, desde os primórdios da evolução até hoje, expressando-se diversificadamente e com significados próprios no contexto de grupos culturais específicos (Daolio, 2007, p. 2)

$\mathrm{O}$ autor conclui que o professor de educação física não atua sobre o corpo ou com o movimento em si, e sim com o ser humano nas suas manifestações culturais relacionadas ao corpo e ao movimento humano historicamente definido como jogo, esporte, dança, luta e ginástica.

Nesse sentido, é necessário resgatar e vivenciar as questões das contribuições dos estudos culturais voltados para as questões corporais nos aspectos que façam com que as pessoas compreendam a relação existente sobre os padrões de estética, cultura, sujeitos, contextos sociais, ou seja, características puramente humanas. Sendo papel fundamental da educação física nos distintos seguimentos sociais a que ela esteja inserida.

Ao analisar corpo e estética é importante relacionar a influência da indústria cultural na construção da imagem corporal e nas práticas corporais. 
Por ser peça vital na engrenagem dos padrões corporais atuais, que deveram ser delineados, delgados e longilíneos, e isso acarreta inúmeras complicações ao estado de saúde, podendo causar na pessoa doenças: anorexia, bulimia, vigorexia e ortorexia.

Assim sendo é necessário que a Educação Física tenha uma postura critica e reflexiva sobre os riscos na busca desenfreada pelo corpo ideal, e os profissionais que atuam nessa área em não reproduzem estereótipos e ideias fragmentadas de corpos belos a qualquer custo.

Em função das inúmeras possibilidades de intervenção da educação física, está em espaços escolares como os não escolares (academias, clubes, departamentos públicos), difundindo ideais na saúde, estética, esporte e lazer. Dessa forma ela se torna mais uma reprodutora dos ideais de consumo da indústria cultural, por ter uma ação muito alienada e fragmentada, pois o que predomina são as questões mercadológicas, de venda e consumo desenfreado.

Quanto mais firmes se tornam as posições da indústria cultural, mais sumariamente ela pode proceder com as necessidades dos consumidores, produzindo-as, dirigindo-as, disciplinando-as e, inclusive suspendendo a diversão: nenhuma barreira se eleva contra o progresso cultural (Adorno; Horkheimer, 1985, p.135).

Como é o objetivo central da indústria cultural é vender mercadorias, o corpo vive na vitrine central, onde é admirado e endeusado, para isso usam-se de todos os recursos, principalmente os midiáticos, com o auxilio da publicidade seu carro chefe.

Contudo, quero destacar também o que considero ser o perigo especifico. Trata-se de algo relativo ao conteúdo, que nada mais tem a ver como veiculo técnico de comunicação de massa. Trata-se destas situações inacreditáveis falsas, em que aparentemente certos problemas são tratados, discutidos e apresentados, para que a situação pareça ser atual e as pessoas sejam confrontadas com questões substantivas. (....). Eis aqui o terrível mundo dos modelos ideais de uma vida saudável, dando os homens uma imagem falsa do que seja a vida de verdade, e que além disto dando a impressão de que as contradições presentes desde os primórdios de nossa sociedade poderiam ser superadas e solucionadas no plano das relações inter-humanas, na medida em que tudo dependeria das pessoas (Adorno, 2000, p. 84).

Na relação corpo e ginástica, é nítido a compreensão da historicidade da educação física com os aspectos ginásticos, o controle e domesticação 
dos gestos motores em função da sua gênese no militarismo, sendo assim concebido de forma mecânica e devendo atingir a excelência na eficácia motora, não gastando alem do recomendado gasto energético para assim atender o novo modelo de sociedade, e hodiernamente há uma controvérsia, pois e função da educação física educar o físico, recaindo na análise da temática anterior.

Foucault, (1987) descreve a relação existente entre a ginástica, os exercícios, o desenvolvimento muscular, a nudez, a exaltação do belo corpo, este ultimo um legado dos gregos, que toma aspectos deformantes no século XIX, sendo fonte de consumo a todo e qualquer preço, mesmo que perca a vida, vive-se em função dessa exaltação do belo corpo, a ditadura do corpo que acarreta nas pessoas inúmeras patologias: anorexia, bulimia, vigorexia, ortorexia, que está saindo ao controle dos discursos dominantes.

Segundo Soares (2007), os primórdios da ginástica esteve relacionado a questões militares, e diretamente ligada as questões de controle das praticas corporais da sociedade européia, e no âmbito educacional ganha espaço ao que refere-se a necessidade de manter o corpo reto e rígido, atendendo assim a perspectiva do positivismo, e tendo a ginástica características ordenativas, disciplinadoras e metódicas caiu como uma luva para atende a ordem vigente para controlar a população que habitava os grandes centros urbanos, atendendo assim a preservação da saúde, que era fundamentada pela ciência positiva, algo totalmente diferente da arte funambulesca, que tinha os corpos soltos e sem nenhuma métrica corporal. Esse contexto se da em função da filosofia positivista, que dará embasamento cientifico as ciências biomédicas, em especial a medicina que cria o discurso de responsabilidade com o corpo a cerca das questões higienistas.

\section{Considerações finais}

Podemos perceber que artigos voltados para a temática corpo na RBCE e Revista Movimento, tem privilegiado as discussões voltados para a área pedagógica e as discussões teóricas do corpo enquanto objeto cultural, assim como está relacionada com um diversidade de temas, tais como: Estética, Saúde, Trabalho, Gênero, e Ginástica. Os autores com maior número de 
ocorrência foram: Carmem Lúcia Soares (8 artigos) e Alexandre Vaz (6 artigos) em ambas revistas.

Notamos que há uma concentração regional no que tange a discussão sobre corpo nas regiões Sudeste e Sul. A região Sudeste apresentou o maior número de instituições que os autores estão vinculados com 35 ocorrências (55\%), destas 17 são do Estado de São Paulo, e a instituição com maior ocorrência foi a UNICAMP, com 8 ocorrências. Na Região Sul a distribuição do vínculo das instituições por Estado, demonstrou que Santa Catarina (12 ocorrências), Rio Grande do Sul (08 ocorrências) e Paraná (3 ocorrências). Destacamos o fato de todas as ocorrências de Santa Catarina serem da Universidade Federal de Santa Catarina. Este dado expressa a necessidade de expandir tal discussão para demais regiões.

Contudo, as temáticas sobre o corpo nos permitiram fazer uma relação de disciplina dos corpos na sociedade atual que visa por meio do discurso e práticas coercitivas, dominarem os corpos desde o inicio da escolarização, onde os passos dos alunos são milimetricamente vigiados, seus discursos posturas são analisados não podendo sair dos padrões estabelecidos. Além disso, as manobras políticas sobre o corpo e a saúde, tentam ressaltar que é o simples conhecimento dessas práticas saudáveis que a população alcançaria as almejadas regras do "bem viver", responsabilizando-as por isso. Porém, como observou Soares (2007) não é o simples conhecimento dessas práticas, mas, sobretudo, as condições sociais e as diferenças de classes que impossibilitam tal acesso.

De fato, a Educação Física desde o final do século XIX até o inicio do século XX com o advento das revoluções, têm sido foi marcada pela educação de um corpo forte, saudável, higiênico, biológico, submisso, controlado, que respondesse aos anseios de um novo homem almejado pela sociedade capitalista.

\section{Referências}

ADORNO, T. W., HORKHEIMER, M. Dialética do esclarecimento: fragmentos filosóficos. Trad. Guido Antonio de Almeida. Rio de Janeiro: Jorge Sahar, 1985

ADORNO, T. W., HORKHEIMER, M. Educação e emancipação. 2.ed. Rio de 
Janeiro: Paz e terra, 2000.

BAPTISTA, T. J. R. Educação do corpo: produção e reprodução. Tese (Doutorado em Educação), Universidade Federal de Goiás, Goiânia, 2007.

BARDIN, L. Análise de conteúdo. Lisboa: Edições 70, 2006. 223p.

BRANDÃO, C. da F. Batendo bola batendo cabeça: problemas da pesquisa em Educação Fisica no Brasil. Ibitinga, SP: Humanidades, 1994.

BRUHNS, H. T. (org). Conversando sobre o corpo. $7^{\mathrm{a}}$ ed. Campinas, SP: Papirus, 1997.

BRITO NETO, A. C. et al. Produção do conhecimento sobre formação de professores de educação física em periódicos científicos análise da revista Movimento (1994-2008). In: CONGRESSO BRASILEIRO DE CIÊNCIAS DO ESPORTE, XVI, CONGRESSO INTERNACIONAL DE CIÊNCIAS DO ESPORTE, III, Salvador, 25 a 29 de Setembro de 2009. Anais... Salvador: CBCE, 2009, p. 1-14. Disponível em:

http://www.rbceonline.org.br/congressos/index.php/CONBRACE/XVI/pa per/viewFile/1688/679. Acesso em: 12 de Janeiro de 2012.

IVANCHEVA, L. Scientometrics today: a methodological overview. In: 4th. International Conference on Webometrics, Informetrics, and Scientometrics. Berlin, 28 jul-1 aug. 2011. Disponível em: http://www.collnet.de/Berlin2008/IvanchevaWIS2008stm.pdf .

CARMO JUNIOR, W. do. Dimensões Filosóficas da Educação Física. Rio de Janeiro; Guanabara Koogan, 2005.

DAOLIO, J. Da cultura do corpo. $7^{\text {a }}$ ed. Campinas, SP: Papirus, 2003.

DAOLIO, J. Educação Física e o Conceito de Cultura: polêmicas do nosso tempo. Campinas, SP: Autores Associados, 2.ed.2007.

FOUCAULT, M. Microfísica do poder. Rio de Janeiro: Graal, 1986.

FOUCAULT, M. Vigiar e punir: O nascimento da prisão. Petropolis: Vozes, 1987.

GONÇALVES, M. A. S. Sentir, pensar, agir. Campinas, SP: Papirus.2 ed.1997

MANACORDA, M. A. História da educação: da antiguidade aos nossos dias. 9.ed.São .Paulo:Cortez,2001

MEDINA, J. P. S. A Educação Física cuida do corpo e 'mente'. $18^{a}$ ed. Campinas, SP: Papirus 1997.

MEDINA, J. P. S. O Brasileiro e seu corpo: Educação e política do corpo. $5^{\text {a }}$ ed. Campinas, SP: Papirus, 1998.

PERROT, M. Os excluidos da história: Operários, mulheres e prisioneiros. Rio de Janeiro: Paz e Terra, 1988. 
ROMERO, E. (org). Corpo mulher e sociedade. Campinas, SP: Papirus, 1995.

SILVA, Ana Márcia. "Das práticas corporais ou por que 'Narciso' se exercita”. Revista Brasileira de Ciencias do Esporte. Florianopolis: CBCE/Unijui, 17(3), maio/1996, PP.244-251

SOARES, C. L. Educação Física: raízes européias e Brasil. $2^{\mathrm{a}}$ ed. rev - Campinas, SP: Autores associados, 2007.

SOARES, C. L. (Org.). Corpo e história. Campinas: Autores Associados, 2001b

SOARES, C. L. Imagens da educação do corpo. $2^{\mathrm{a}}$ ed. rev. - Campinas, SP: Autores Associados, 2002.

VAZ, A. F. Treinar o corpo, dominar a natureza: notas para uma análise do esporte com base no treinamento corporal. Cadernos Cedes, Campinas, v.19, n. 48, p. 89-108, ago., 1999. 